\title{
Transtornos de humor em pacientes com alterações neuropsicológicas: uma revisão integrativa da literatura
}

\author{
Mood disorders in patients with neuropsychological disorders: an integrative literature review \\ Trastornos del estado de ánimo en pacientes con trastornos neuropsicológicos: una revisión
}

integradora de la literature

Recebido: 10/01/2022 | Revisado: 14/01/2022 | Aceito: 27/01/2022 | Publicado: 28/01/2022

\author{
Adelino Domingos Onofre \\ ORCID: https://orcid.org/0000-0002-5262-7572 \\ Universidade Federal de Santa Catarina, Brasil \\ E-mail: adelinoonofre@gmail.com \\ Roberto Moraes Cruz \\ ORCID: https://orcid.org/0000-0003-4671-3498 \\ Universidade Federal de Santa Catarina, Brasil \\ E-mail: robertocruzdr@gmail.com \\ Rachel Schlindwein Zanini \\ ORCID: https://orcid.org/0000-0002-9152-9860 \\ Universidade Federal de Santa Catarina, Brasil \\ E-mail: rachelz@ floripa.com.br \\ Fernanda Pereira Labiak \\ ORCID: https://orcid.org/0000-0002-8272-711X \\ Universidade Federal de Santa Catarina, Brasil \\ E-mail: fernanda_labiak@yahoo.com.br
}

\begin{abstract}
Resumo
O objetivo deste estudo foi analisar as contribuições científicas sobre sintomas de transtornos de humor em pacientes com alterações neuropsicológicas, em âmbito nacional e internacional. Foi realizada uma Revisão Integrativa da Literatura, seguindo o delineamento Preferred Reporting Items for Systematic Reviews and Meta-Analyses (PRISMA), por meio das seguintes bases eletrônicas: Scopus, PubMed, Web of Science, Portal BVS e PsyNet, a partir dos descritores: "mood" and "neuropsychological disorder" or "neuropsychological disease" or "neuropsychological disturb". Após a aplicação dos critérios de inclusão e exclusão, foram selecionados 42 artigos, 24 sobre transtornos do humor (bipolar, depressão, impulsividade, anedonia, ansiedade, insegurança, desesperança e afetividade) e 18 sobre transtornos neuropsicológicos (esclerose múltipla, demência, doença de Parkinson, doença de Alzheimer, esquizofrenia, doenças vasculares e cardiovasculares). Os resultados mostram a importância do aprofundamento das pesquisas sobre transtornos de humor e transtornos neuropsicológicos, pois impactam negativamente na vida dos indivíduos, com destaque para a esfera cognitiva, incluindo as funções executivas, essenciais para o bem-estar e a convivência social.
\end{abstract}

Palavras-chave: Transtornos de humor; Neuropsicologia; Funções cognitivas.

\begin{abstract}
The aim of this study was to analyze the scientific contributions on symptoms of mood disorders in patients with neuropsychological alterations, in national and international scope. An Integrative Literature Review was carried out, following the Preferred Reporting Items for Systematic Reviews and Meta-Analyses (PRISMA), through the following electronic databases: Scopus, PubMed, Web of Science, Portal BVS and PsyNet, using the descriptors: "mood" and "neuropsychological disorder" or "neuropsychological disease" or "neuropsychological disturb". After applying the inclusion and exclusion criteria, 42 articles were selected, 24 on mood disorders (bipolar, depression, impulsiveness, anhedonia, anxiety, insecurity, hopelessness, and affectivity) and 18 on neuropsychological disorders (multiple sclerosis, dementia, Parkinson's disease, Alzheimer's disease, Schizophrenia, vascular and cardiovascular disease). The results showed the importance of deepening the investigations related to mood disorders and neuropsychological alterations, since they negatively impact the individual's life, with emphasis on the cognitive sphere and executive functions, which are essential for well-being and coexistence Social.
\end{abstract}

Keywords: Mood disorders; Neuropsychology; Cognitive functions.

\section{Resumen}

El objetivo de este estudio fue analizar las contribuciones de artículos publicados a nivel nacional e internacional sobre los síntomas de los trastornos del estado de ánimo en pacientes con trastornos neuropsicológicos. Se realizó una 
Revisión Integrativa de la Literatura, siguiendo el Preferred Reporting Items for Systematic Reviews and MetaAnalyses (PRISMA), a través de las siguientes bases de datos electrónicas: Scopus, PubMed, Web of Science, Portal BVS y PsyNet, utilizando los descriptores: "mood" and "neuropsychological disorder" or "neuropsychological disease" or "neuropsychological disturb". Tras aplicar los criterios de inclusión y exclusión, se seleccionaron 42 artículos, 24 sobre trastornos del estado de ánimo (bipolar, depresión, impulsividad, anhedonia, ansiedad, inseguridad, desesperanza y afectividad) y 18 sobre trastornos neuropsicológicos (esclerosis múltiple, demencia, enfermedad de Parkinson, enfermedad de Alzheimer, esquizofrenia, enfermedad vascular y cardiovascular). Los resultados evidenciaron la importancia de profundizar las investigaciones relacionadas con los trastornos del estado de ánimo y las alteraciones neuropsicológicas, ya que impactan negativamente en la vida del individuo, con énfasis en la esfera cognitiva y las funciones ejecutivas, que son fundamentales para el bienestar y la convivencia social.

Palabras clave: Trastornos del estado de ánimo; Neuropsicología; Funciones cognitivas.

\section{Introduçãa}

Os transtornos de humor têm por principal característica a alteração no humor ou no afeto, comportamento, jeito de sentir e pensar, ou seja, afetam as funções cognitivas, prejudicando a atenção, a velocidade de processamento de informação, a fluência verbal e a resistência na interferência à estímulos. São considerados agravos à saúde mental nos quais as alterações de humor e afeto e podem se prolongar entre períodos de depressão e exaltação excessiva ou de euforia, ou ambos (American Psychiatric Association, 2014; Medrano-Martinez et al., 2018). As causas e os efeitos dos transtornos de humor devem ser entendidos, levando em consideração as dimensões biológicas, psicológicas e sociais dos indivíduos.

A compreensão dos transtornos de humor é essencial uma vez que os seus sintomas podem ser severos, e estima-se que cerca de $8 \%$ da população poderá vivenciá-los em algum momento da vida. Os diagnósticos de transtornos mentais são feitos a partir de sintomas presentes na vida do sujeito e, geralmente, são embasados no Manual Diagnóstico e Estatístico de Transtornos Mentais (DSM) e na Classificação Internacional de Doenças e Problemas Relacionados à Saúde (CID). O DSM-V classifica os transtornos de humor em dois grandes grupos, sendo o transtorno bipolar e os relacionados ao transtorno depressivo (APA, 2014). A CID-10, publicada pela Organização Mundial de Saúde (OMS), padroniza a codificação dos transtornos do humor de F30 a F39, compreendendo episódio maníaco, transtorno afetivo bipolar, episódio depressivos, transtorno depressivo recorrente, transtorno de humor persistentes, outros transtornos de humor e transtorno do humor não especificado.

Os transtornos de humor são diagnosticados, em sua maioria, quando a tristeza ou a euforia é excessivamente intensa, podendo ser acompanhada por determinados sintomas típicos, que comprometem a capacidade funcional, física, psicológica e social. Entender as manifestações de transtornos de humor atrelados às alterações neuropsicológicas é fundamental para identificar biomarcadores úteis no intuito de: agilizar o diagnóstico precoce e melhorar a compreensão da progressão dos transtornos de humor e das diversas formas de alterações neuropsicológicas; monitorar com maior precisão a resposta terapêutica ao tratamento e; desenvolver intervenções modificadoras das doenças precoces, oferecendo aos pacientes uma forma de acompanhamento paralelo ao tratamento médico, a fim de minimizar os efeitos psicológicos e sociais.

As alterações neuropsicológicas podem ser descritas em termos de uma ampla variedade de características clínicas que incluem sinais e sintomas no processamento cerebral, especialmente no domínio cognitivo e nas respostas emocionais, implicando em déficits nas funções executivas e explicando dificuldades na adaptação pessoal à vida diária. As alterações neuropsicológicas nos transtornos de humor ocorrem de várias formas e podem ser intensificadas com comorbidades como esclerose múltipla, demência, doença de Alzheimer, doença de Parkinson e esquizofrenia etc. Existe uma imensa quantidade de informações relacionadas a alterações neuropsicológicas nos transtornos de humor e comorbidades, a partir disso, foi analisar as contribuições científicas sobre sintomas de transtornos de humor em pacientes com alterações neuropsicológicas, em âmbito nacional e internacional. 


\section{Metodologia}

O método usado nesta revisão foi Preferred reporting items for systematic reviews and meta-analyses - PRISMA (Moher et al., 2009), frequentemente utilizado na literatura científica para revisões sistemáticas e meta análises. A sequência utilizada para análise dos estudos foram: título, resumo estruturado, introdução (justificativa e objetivos), métodos (critério de elegibilidade, fontes de informação, busca, seleção de estudos, processo de coleta de dados, lista dos dados, síntese dos resultados, análises adicionais, resultados (seleção dos estudos, caraterísticas dos estudos), discussão (sumário de evidências, limitações, conclusões) e o financiamento da pesquisa.

Neste estudo, foram contemplados três aspectos metodológicos qualitativos utilizados como critérios básicos: 1) artigos com identificação dos procedimentos de amostragem, mesmo que não tenha sido probabilística; 2) artigos que apresentavam informações com consistência interna das medidas utilizadas; e 3) pesquisas cujo dados de prevalência e incidência foram apresentados. A pesquisa foi realizada nas bases de dados Scopus, PubMed, Web of Science, Portal BVS e PsyNet, teve como critérios de busca, as palavras-chaves mood AND neuropsychological disorder OR neuropsychological disease OR neuropsychological disturb e artigos publicados em inglês, espanhol e português entre os anos de 2015 e 2019. A escolha dessas bases de dados se deu devido a sua abrangência internacional de publicações em periódicos de alto impacto e, também por contemplar estudos em saúde e em psicologia (Gomes \& Caminha, 2014).

Os critérios de seleção dos artigos abrangeram a leitura prévia dos títulos, assuntos, resumos e palavras chaves. Dos artigos que contemplavam a temática estudada foram selecionados: a) os empíricos e revisões de literatura; b) os que continham público-alvo composto por pacientes com alterações neuropsicológicas; e c) os que apresentam indicadores de transtornos de humor, independente de demais comorbidades. A Figura 1 mostra o fluxograma da revisão sistemática, seguindo o modelo PRISMA.

Figura 1. Fluxograma da revisão sistemática.

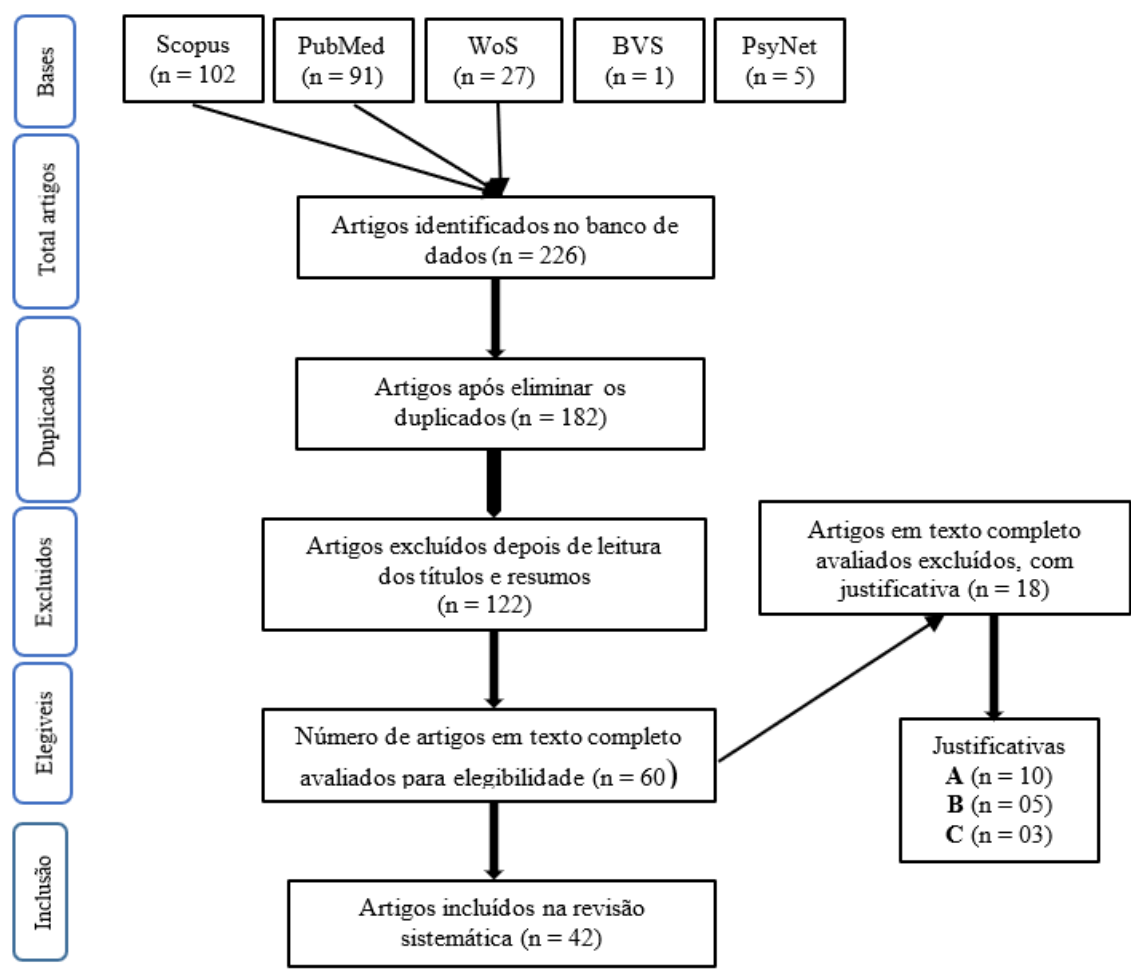

Legenda: A = Artigos que não abordam a temática; $\mathbf{B}=$ os não retratam alterações neuropsicológicas com variável dependente e $\mathbf{C}=$ aqueles que não apresentaram indicadores de transtornos de humor. Fonte: Autores. 
O período da busca sistemática compreendeu 2 de janeiro a 30 janeiro 2020, e foram selecionados 226 artigos, distribuídos da seguinte forma: Scopus $=102$, PubMed $=91$, Web of Science $=27$, Portal BVS $=1$, e PsyNet $=5$. Do quantitativo total, foram excluídos 39 artigos duplicados, 127 artigos não tiveram critérios de elegibilidade: a) não abordam a temática; b) não retratam alterações neuropsicológicas como variável dependente; e c) pouca relação com os transtornos de humor. Os 60 artigos restantes foram lidos na íntegra e excluídos 18 por não ter elegibilidade, sobrando 42 artigos que fizeram parte deste estudo.

\section{Resultados e Discussão}

Ao analisar por continente os 42 estudos encontrados, a América saiu na dianteira com (n=23), seguida por Europa com ( $n=14)$, Oceania ( $n=4)$ e Ásia $(n=1)$. A América foi representada por quatro países: Brasil, Estados Unidos, Argentina e Canadá. No lado Europeu Inglaterra, Irlanda do Norte, França, Suíça e Holanda. A Oceania, representada pela Austrália. Quanto a evolução por anos, ficou demonstrado uma produção temporal irregular ao longo dos anos, com destaque para 2019 ( $(\mathrm{n}=12) ; 2015$ e $2017(\mathrm{n}=$ 9); $2016(\mathrm{n}=7)$ e o ano 2018 com menos produção $(\mathrm{n}=5)$. No que tange a contribuição por países, o Brasil está representado em 14 estudos, os Estados Unidos e a Inglaterra em 7 estudos, a Austrália em 4 estudos, a Irlanda do Norte e o Canadá em 2 estudos, a Argentina, a França, a Suíça, a Holanda, a China e a Alemanha em 1 estudo.

A metodologia adotada nos artigos selecionados contempla 26 revisões sistemáticas, 4 revisões sistemáticas e metaanálises, 3 meta-análises, 2 estudos transversais e longitudinais, 2 estudos longitudinais, 2 estudos voltados para intervenção, 1 revisão sistemática PRISMA, 1 revisão sistemática e intervenção, e 1 estudo direcionado na validade interna e externa. As tabelas 1 e 2 mostram a categorização dos artigos.

Tabela 1. Informações dos estudos selecionados sobre transtornos de humor em termos de autores, tipo de estudo, objetivo, amostra, palavras-chaves e resultados.

\begin{tabular}{|c|c|c|c|c|c|}
\hline Autores & $\begin{array}{c}\text { Tipo de estudo: } \\
\text { transtorno } \\
\text { humor }\end{array}$ & Objetivo & $\begin{array}{c}\text { Amos- } \\
\text { tra }\end{array}$ & Palavras-Chaves & Resultados \\
\hline $\begin{array}{l}\text { Baune e } \\
\text { Malhi. } \\
(2015) \\
\text { Austrália }\end{array}$ & $\begin{array}{l}\text { Transversal e } \\
\text { Longitudinal } \\
\text { Transtorno } \\
\text { Bipolar }\end{array}$ & $\begin{array}{l}\text { Examinar a } \\
\text { literatura sobre as } \\
\text { relações entre a } \\
\text { função cognitiva e a } \\
\text { função geral nas } \\
\text { fases clínicas do } \\
\text { Transtorno Bipolar }\end{array}$ & $\begin{array}{c}18 \\
\text { Estudos }\end{array}$ & $\begin{array}{l}\text { Doença } \\
\text { cardiovascular. } \\
\text { Doença cardíaca. } \\
\text { Doença vascular. } \\
\text { Derrame. } \\
\text { Ataque isquêmico } \\
\text { transitório. }\end{array}$ & $\begin{array}{l}\text { Existência de uma relação consistente entre a } \\
\text { função social, ocupacional e o desempenho } \\
\text { cognitivo, a execução é afetada por déficits } \\
\text { cognitivos nos Transtornos Bipolar }\end{array}$ \\
\hline $\begin{array}{l}\text { Bosaipo et } \\
\text { al. (2017) } \\
\text { Brasil }\end{array}$ & $\begin{array}{l}\text { Revisão } \\
\text { sistemática }\end{array}$ & $\begin{array}{l}\text { Revisar } \\
\text { sistematicamente e } \\
\text { analisar criticamente } \\
\text { a literatura sobre a } \\
\text { função cognitiva em } \\
\text { pacientes com } \\
\text { depressão } \\
\text { melancólica e } \\
\text { atípica }\end{array}$ & $\begin{array}{c}17 \\
\text { Estudos }\end{array}$ & $\begin{array}{l}\text { Depressão. } \\
\text { Melancolia. }\end{array}$ & $\begin{array}{l}\text { Pacientes melancólicos } \\
\text { maiores deficiências neuropsicológicas } \\
\text { quando comparados (MEL) com os não } \\
\text { melancólicos (NMEL) e os não clínicos } \\
\text { (NC) em tarefas que requerem memória, } \\
\text { função executiva, atenção e tempo de reação }\end{array}$ \\
\hline $\begin{array}{l}\text { Bortolini. } \\
(2016)\end{array}$ & $\begin{array}{l}\text { Revisão } \\
\text { sistemática } \\
\text { Tentativa de } \\
\text { suicido }\end{array}$ & $\begin{array}{l}\text { Conhecer as } \\
\text { características } \\
\text { bibliométricas e } \\
\text { identificar os fatores } \\
\text { associados ao } \\
\text { suicídio entre os } \\
\text { idosos }\end{array}$ & $\begin{array}{c}38 \\
\text { Estudos }\end{array}$ & $\begin{array}{l}\text { Suicídio. } \\
\text { Pessoa idosa. } \\
\text { Fatores de Risco. }\end{array}$ & $\begin{array}{l}\text { Os fatores psicológicos e psiquiátricos os } \\
\text { mais associados ao suicídio; a depressão é } \\
\text { destacada em } 26,3 \% \text {, tentativa de suicídio } \\
\text { prévia e transtorno de humor - ambos com } \\
15,8 \% \text {. Os fatores sociais associados à } \\
\text { morte recente de familiares (11,4\%), os } \\
\text { aspectos financeiros e falta de apoio, ambos } \\
\text { com } 10,5 \% \text {. Os fatores clínicos, doenças } \\
\text { crônicas com } 28,9 \% \text {; dor crônica, } 7,8 \% \text { e o } \\
\text { comprometimento funcional, } 2,6 \%\end{array}$ \\
\hline
\end{tabular}




\begin{tabular}{|c|c|c|c|c|c|}
\hline $\begin{array}{l}\text { Bresin } \\
(2019) \\
E U A\end{array}$ & $\begin{array}{l}\text { Meta-análise } \\
\text { Impulsividade }\end{array}$ & $\begin{array}{l}\text { Determinar a relação } \\
\text { entre as diferentes } \\
\text { facetas da } \\
\text { impulsividade (ou } \\
\text { seja, urgência } \\
\text { negativa, urgência } \\
\text { positiva, falta de } \\
\text { premeditação, falta } \\
\text { de perseverança e } \\
\text { busca de sensação) e } \\
\text { agressão }\end{array}$ & $\begin{array}{c}93 \\
\text { Estudos }\end{array}$ & $\begin{array}{l}\text { Impulsividade. } \\
\text { Agressão. } \\
\text { Meta-análise. } \\
\text { Urgência negativa. }\end{array}$ & $\begin{array}{l}\text { Mostraram correlações significativas e } \\
\text { pequenas a médias entre cada faceta da } \\
\text { impulsividade e agressão em várias formas } \\
\text { diferentes de agressão, com mais } \\
\text { impulsividade sendo associada a mais } \\
\text { agressão. Urgência negativa, urgência } \\
\text { positiva e falta de premeditação tiveram } \\
\text { associações significativamente mais fortes } \\
\text { com agressão }\end{array}$ \\
\hline $\begin{array}{l}\text { Cambridge } \\
\text { et al. } \\
\text { (2018) } \\
\text { Austrália }\end{array}$ & $\begin{array}{l}\text { Revisão } \\
\text { sistemática } \\
\text { Transtorno } \\
\text { Depressivo } \\
\text { Maior (TDM) }\end{array}$ & $\begin{array}{l}\text { Revisar } \\
\text { sistematicamente a } \\
\text { literatura sobre a } \\
\text { relação entre } \\
\text { deficiências } \\
\text { cognitivas } \\
\text { específicas e } \\
\text { funcionamento } \\
\text { psicossocial no } \\
\text { TDM }\end{array}$ & $\begin{array}{c}28 \\
\text { Estudos }\end{array}$ & $\begin{array}{l}\text { Depressão. } \\
\text { Transtornos } \\
\text { depressivos maiores. } \\
\text { Cognição. } \\
\text { Função executiva. }\end{array}$ & $\begin{array}{l}\text { Déficits cognitivos nos domínios do } \\
\text { funcionamento executivo, atenção, memória } \\
\text { e cognição global estão associados à } \\
\text { disfunça psicossocial em domínios como } \\
\text { qualidade de vida e funcionamento social, } \\
\text { ocupacional e global. Idade mais avançada e } \\
\text { maior gravidade dos sintomas de TDM } \\
\text { parecem aumentar a relação cognição- } \\
\text { disfunção psicossocial }\end{array}$ \\
\hline $\begin{array}{l}\text { Cao et al } \\
(2019) \\
\text { China }\end{array}$ & $\begin{array}{l}\text { Revisão } \\
\text { sistemática } \\
\text { Anedonia }\end{array}$ & $\begin{array}{l}\text { Avaliar a eficácia } \\
\text { terapêutica dos } \\
\text { tratamentos } \\
\text { farmacológicos nas } \\
\text { medidas de anedonia } \\
\text { em adultos com } \\
\text { TDM }\end{array}$ & $\begin{array}{c}17 \\
\text { Estudos }\end{array}$ & $\begin{array}{l}\text { Antidepressivo. } \\
\text { Transtorno } \\
\text { Depressivo Maior. } \\
\text { Anedonia. } \\
\text { Agomelatina. } \\
\text { A escala de prazer } \\
\text { Snaith-Hamilton. }\end{array}$ & $\begin{array}{l}\text { Com base nas evidências disponíveis, a } \\
\text { maioria dos antidepressivos demonstrou } \\
\text { efeitos benéficos nas medidas de anedonia, } \\
\text { bem como em outros sintomas depressivos. } \\
\text { Apenas o tratamento combinado de } \\
\text { escitalopram / riluzol foi ineficaz no } \\
\text { tratamento dos sintomas de anedonia em } \\
\text { TDM. }\end{array}$ \\
\hline $\begin{array}{l}\text { Cardoso et } \\
\text { al. (2015) } \\
\text { EUA }\end{array}$ & $\begin{array}{l}\text { Transversal e } \\
\text { Longitudinal } \\
\text { Transtorno } \\
\text { Bipolar (TB) }\end{array}$ & $\begin{array}{l}\text { Examinar a } \\
\text { literatura em relação } \\
\text { aos potenciais } \\
\text { mecanismos que } \\
\text { explicam o declínio } \\
\text { cognitivo nos TB }\end{array}$ & $\begin{array}{c}39 \\
\text { Estudos }\end{array}$ & $\begin{array}{l}\text { Transtorno bipolar. } \\
\text { Conhecimento. } \\
\text { Envelhecimento. } \\
\text { Neuroprogressão. }\end{array}$ & $\begin{array}{l}\text { O declínio cognitivo está relacionado com } \\
\text { número de episódios de hospitalização e } \\
\text { curso da doença }\end{array}$ \\
\hline $\begin{array}{l}\text { Clemente et } \\
\text { al. (2019) } \\
\text { Brasil }\end{array}$ & $\begin{array}{l}\text { Revisão } \\
\text { sistemática } \\
\text { Transtorno de } \\
\text { ansiedade }\end{array}$ & $\begin{array}{l}\text { Verificar estudos no } \\
\text { período de 2006- } \\
\text { 2016, que discutem } \\
\text { formas de avaliação } \\
\text { e intervenção sobre } \\
\text { a ansiedade em } \\
\text { atletas e praticantes } \\
\text { de exercício físico }\end{array}$ & $\begin{array}{c}39 \\
\text { Estudos }\end{array}$ & $\begin{array}{l}\text { Ansiedade. } \\
\text { Exercício. } \\
\text { Dança. Atletas. } \\
\text { Psicologia do } \\
\text { Esporte. }\end{array}$ & $\begin{array}{l}\text { Os resultados do presente estudo são de } \\
\text { fundamental importância por poderem } \\
\text { proporcionar novos parâmetros sobre os } \\
\text { fatores individuais intervenientes na } \\
\text { percepção da ansiedade em atletas de } \\
\text { diferentes modalidades esportivas e suas } \\
\text { relações com os diferentes tipos de } \\
\text { ansiedade ao longo de uma competição }\end{array}$ \\
\hline $\begin{array}{l}\text { de Lima } \\
\text { Argimon. et } \\
\text { al. (2016) } \\
\text { Brasil }\end{array}$ & $\begin{array}{l}\text { Revisão } \\
\text { sistemática } \\
\text { Transtorno } \\
\text { depressivo }\end{array}$ & $\begin{array}{l}\text { Caracterizar as } \\
\text { amostras de idosos, } \\
\text { se clínicas ou não, a } \\
\text { finalidade do uso } \\
\text { instrumento, bem } \\
\text { como os locais de } \\
\text { recrutamento dos } \\
\text { participantes }\end{array}$ & $\begin{array}{c}8 \\
\text { Estudos }\end{array}$ & $\begin{array}{l}\text { Inventário de } \\
\text { Depressão de Beck. } \\
\text { Depressão. } \\
\text { Idosos. }\end{array}$ & $\begin{array}{l}\text { Verificou-se que a aplicabilidade do BDI-II } \\
\text { ocorre tanto com idosos saudáveis quanto } \\
\text { idosos de grupos clínicos, em diversos } \\
\text { contextos. Para o grupo clínico BDI-II usou- } \\
\text { se para idosos com depressão, doença de } \\
\text { Parkinson, Alzheimer, declínio cognitivo } \\
\text { leve, distúrbio de sono e Esclerose Múltipla }\end{array}$ \\
\hline $\begin{array}{l}\text { de Oliveira } \\
\text { Miranda et } \\
\text { al. (2018) } \\
\text { Brasil }\end{array}$ & $\begin{array}{l}\text { Revisão } \\
\text { sistemática } \\
\text { Tentativa de } \\
\text { Suicídio }\end{array}$ & $\begin{array}{l}\text { Entender e pontuar a } \\
\text { prevalência do } \\
\text { comportamento de } \\
\text { ideação suicida em } \\
\text { jovens universitários }\end{array}$ & $\begin{array}{c}8 \\
\text { Estudos }\end{array}$ & $\begin{array}{l}\text { Atentado suicida. } \\
\text { Adulto jovem. } \\
\text { Suicídio. } \\
\text { Universitário. } \\
\text { Ideação suicida. }\end{array}$ & $\begin{array}{l}\text { Analisou-se a presença de fatores externos } \\
\text { associados às causas prevalentes para a ideia } \\
\text { de suicídio, estando dentre eles: o abuso de } \\
\text { drogas lícitas e ilícitas; pressão da faculdade } \\
\text { e conflitos familiares; e, por fim, fatores } \\
\text { internos como saúde mental debilitada e } \\
\text { depressão }\end{array}$ \\
\hline $\begin{array}{l}\text { Dickinso, } \\
\text { Becerra e } \\
\text { Jacqui. } \\
\text { (2017) } \\
\text { Irlanda do } \\
\text { Norte } \\
\end{array}$ & $\begin{array}{l}\text { Revisão } \\
\text { Sistemática e } \\
\text { Meta-Análise } \\
\text { Transtorno } \\
\text { Bipolar I e II. }\end{array}$ & $\begin{array}{l}\text { Avaliar se existem } \\
\text { déficits na função } \\
\text { executiva em } \\
\text { adultos com TB e se } \\
\text { diferem de acordo } \\
\text { com subtipo de TB }\end{array}$ & $\begin{array}{c}36 \\
\text { Estudos }\end{array}$ & $\begin{array}{l}\text { Funcionamento } \\
\text { executivo. } \\
\text { Bipolar } 1 . \\
\text { Bipolar } 2 . \\
\text { Meta-análise. } \\
\text { Revisão sistemática. }\end{array}$ & $\begin{array}{l}\text { Os TBI tiveram pior desempenho nas } \\
\text { habilidades sociais em todos os domínios. Os } \\
\text { TB-II podem experimentar algumas funções } \\
\text { executivas maiores }\end{array}$ \\
\hline $\begin{array}{l}\text { Edwards et } \\
\text { al (2015). }\end{array}$ & $\begin{array}{l}\text { Revisão } \\
\text { sistemática }\end{array}$ & $\begin{array}{l}\text { Revisar } \\
\text { sistematicamente as }\end{array}$ & $\begin{array}{c}85 \\
\text { Estudos }\end{array}$ & $\begin{array}{l}\text { Anedonia. } \\
\text { Esquizofrenia. }\end{array}$ & $\begin{array}{l}\text { As funções executivas, a memória emocional } \\
\text { e a tradução de motivação em ações são }\end{array}$ \\
\hline
\end{tabular}




\begin{tabular}{|c|c|c|c|c|c|}
\hline Inglaterra & Anedonia & $\begin{array}{l}\text { evidências empíricas } \\
\text { para cada } \\
\text { componente do } \\
\text { modelo experiência } \\
\text { temporal de prazer } \\
\text { TEP e propor alvos } \\
\text { terapêuticos } \\
\text { baseados em } \\
\text { evidências para } \\
\text { anedonia e a } \\
\text { motivação na } \\
\text { esquizofrenia. }\end{array}$ & & $\begin{array}{l}\text { Sintomas negativos. } \\
\text { Funções executivas. } \\
\text { Intervenção. } \\
\text { Revisão sistemática. }\end{array}$ & $\begin{array}{l}\text { destacadas como principais déficits com } \\
\text { destaque em pessoas esquizofrênicas }\end{array}$ \\
\hline $\begin{array}{l}\text { Gibson et al } \\
\text { (2018) } \\
\text { Inglaterra }\end{array}$ & $\begin{array}{l}\text { Revisão } \\
\text { sistemática } \\
\text { PRISMA } \\
\text { Afetividade }\end{array}$ & $\begin{array}{l}\text { Avaliar a } \\
\text { prevalência e os } \\
\text { fatores de risco } \\
\text { associados aos } \\
\text { transtornos afetivos } \\
\text { em pacientes adultos } \\
\text { com cicatrizes } \\
\text { faciais }\end{array}$ & $\begin{array}{c}21 \\
\text { Estudos }\end{array}$ & $\begin{array}{l}\text { Ansiedade. } \\
\text { Depressão. } \\
\text { Cicatriz facial. } \\
\text { Trauma facial. } \\
\text { Prevalência. }\end{array}$ & $\begin{array}{l}\text { Usando um modelo de efeitos aleatórios, a } \\
\text { prevalência combinada ponderada de } \\
\text { ansiedade foi de } 26,1 \% \text { (IC } 95 \%, 17,9 \% \text { e - } \\
36,3 \% \text { e a prevalência combinada } \\
\text { ponderada de depressão foi } 21,4 \% \text { (IC } 95 \% \text {, } \\
15,4 \% \text { e }-29,0 \% \text { ). Estudos identificaram } \\
\text { gênero feminino, história psiquiátrica } \\
\text { passada e causalidade violenta como fatores } \\
\text { associados à ansiedade e depressão }\end{array}$ \\
\hline $\begin{array}{l}\text { Gomes e } \\
\text { Ivo (2017) } \\
\text { Brasil }\end{array}$ & $\begin{array}{l}\text { Revisão } \\
\text { sistemática } \\
\text { Transtorno } \\
\text { depressão }\end{array}$ & $\begin{array}{l}\text { Averiguar a } \\
\text { sistematização da } \\
\text { assistência do } \\
\text { enfermeiro em } \\
\text { mulheres com } \\
\text { sintomas } \\
\text { depressivos }\end{array}$ & $\begin{array}{c}13 \\
\text { Estudos }\end{array}$ & $\begin{array}{l}\text { Depressão. } \\
\text { Mulheres. } \\
\text { Sistematização da } \\
\text { assistência de } \\
\text { enfermagem. }\end{array}$ & $\begin{array}{l}\text { As assistências de enfermagem aplicadas em } \\
\text { mulheres com depressão encontradas nesta } \\
\text { revisão foram: escuta qualificada, } \\
\text { musicoterapia, terapia cognitiva } \\
\text { comportamental, biodança e auxílio na } \\
\text { terapia medicamentoso }\end{array}$ \\
\hline $\begin{array}{l}\text { Júnior et } \\
\text { al., (2018) } \\
\text { Brasil }\end{array}$ & $\begin{array}{l}\text { Revisão } \\
\text { sistemática } \\
\text { Desesperança }\end{array}$ & $\begin{array}{l}\text { Analisar a } \\
\text { prevalência de } \\
\text { desesperança em } \\
\text { idosos demonstrar } \\
\text { os problemas que } \\
\text { podem estar } \\
\text { associados a esse } \\
\text { sentimento nessa } \\
\text { população específica }\end{array}$ & $\begin{array}{c}04 \\
\text { Estudos }\end{array}$ & $\begin{array}{l}\text { Idosos. Escala de } \\
\text { Beck. } \\
\text { Desesperança. }\end{array}$ & $\begin{array}{l}\text { A desesperança estava relacionada com } \\
\text { vulnerabilidades patológicas, sociais, } \\
\text { comportamentais e fisiológicas, variando de } \\
\text { acordo com a situação analisada }\end{array}$ \\
\hline $\begin{array}{l}\text { Karantzas, } \\
\text { Romano e } \\
\text { Lee (2019). } \\
\text { Austrália }\end{array}$ & $\begin{array}{l}\text { Revisão } \\
\text { sistemática } \\
\text { Insegurança }\end{array}$ & $\begin{array}{l}\text { Revisar pesquisas } \\
\text { publicadas nos } \\
\text { últimos anos, síntese } \\
\text { qualitativa a artigos } \\
\text { publicados } \\
\text { recentemente }\end{array}$ & $\begin{array}{c}11 \\
\text { Estudos }\end{array}$ & $\begin{array}{l}\text { Apego. } \\
\text { Cuidado. } \\
\text { Casa. } \\
\text { Filhos. } \\
\text { Idoso. } \\
\text { Demência. } \\
\text { Doença crônica. }\end{array}$ & $\begin{array}{l}\text { Para o cuidador, a ansiedade de apego foi } \\
\text { associada a uma pior saúde mental e a } \\
\text { insegurança de apego a uma forma mais } \\
\text { controladora de cuidar. A insegurança de } \\
\text { apego estava associada a uma maior } \\
\text { autoavaliação dos sintomas de demência e a } \\
\text { uma menor sensação de segurança }\end{array}$ \\
\hline $\begin{array}{l}\text { Kliemann, } \\
\text { Böing e } \\
\text { Crepaldi } \\
\text { (2017). } \\
\text { Brasil }\end{array}$ & $\begin{array}{l}\text { Revisão } \\
\text { sistemática } \\
\text { Transtorno de } \\
\text { ansiedade e } \\
\text { depressão }\end{array}$ & $\begin{array}{l}\text { Caracterizar a } \\
\text { produção de artigos } \\
\text { que mensuraram } \\
\text { sintomas de } \\
\text { ansiedade e } \\
\text { depressão na } \\
\text { gestação }\end{array}$ & $\begin{array}{c}41 \\
\text { Estudos }\end{array}$ & $\begin{array}{l}\text { Gravidez. } \\
\text { Ansiedade. } \\
\text { Depressão. } \\
\text { Fatores de risco. }\end{array}$ & $\begin{array}{l}\text { Os fatores socioeconômicos, o histórico de } \\
\text { saúde mental, as complicações obstétricas e } \\
\text { a rede de apoio frágil foram os principais } \\
\text { fatores de risco para sintomas de depressão e } \\
\text { ansiedade na gestação }\end{array}$ \\
\hline $\begin{array}{l}\text { McHugh et } \\
\text { al (2019) } \\
\text { Austrália }\end{array}$ & $\begin{array}{l}\text { Revisão } \\
\text { sistemática e } \\
\text { meta-análise } \\
\text { Impulsividade }\end{array}$ & $\begin{array}{l}\text { Estabelecer se a } \\
\text { idade ou o gênero } \\
\text { modera a relação } \\
\text { entre a } \\
\text { impulsividade e tais } \\
\text { comportamentos. }\end{array}$ & $\begin{array}{c}18 \\
\text { Estudos }\end{array}$ & $\begin{array}{l}\text { Comportamento } \\
\text { suicida. } \\
\text { Auto-mutilação } \\
\text { deliberada. } \\
\text { Autolesão não } \\
\text { suicida. } \\
\text { Jovens. } \\
\text { Adolescente. } \\
\text { Impulsividade. } \\
\text { Desconto de atraso. } \\
\text { Inibição cognitiva. } \\
\text { Inibição da resposta. }\end{array}$ & $\begin{array}{l}\text { Foram associados a automutilação ou } \\
\text { comportamento suicida. Não houve } \\
\text { diferenças significativas entre as medidas } \\
\text { das diferentes facetas da impulsividade e } \\
\text { automutilação ou comportamento suicida. }\end{array}$ \\
\hline $\begin{array}{l}\text { Passos et } \\
\text { al. (2016) }\end{array}$ & $\begin{array}{l}\text { Revisão } \\
\text { sistemática } \\
\text { Transtornos }\end{array}$ & $\begin{array}{l}\text { Revisar as } \\
\text { características } \\
\text { clínicas e biológicas }\end{array}$ & $\begin{array}{c}114 \\
\text { Estudos }\end{array}$ & $\begin{array}{l}\text { Transtorno bipolar. } \\
\text { Neuroprogressão, } \\
\text { Tratamento. }\end{array}$ & $\begin{array}{l}\text { Pacientes com TB apresentam um curso } \\
\text { neuroprogressivo com mudanças cerebrais e } \\
\text { resultados desfavoráveis. Fatores de risco }\end{array}$ \\
\hline
\end{tabular}




\begin{tabular}{|c|c|c|c|}
\hline Brasil & Bipolares & $\begin{array}{l}\text { fundamentos } \\
\text { relacionados à } \\
\text { neuroprogressão no } \\
\text { transtorno bipolar } \\
\text { (TB) }\end{array}$ & \\
\hline $\begin{array}{l}\text { Sami et al. } \\
\text { (2015) } \\
\text { EUA }\end{array}$ & $\begin{array}{l}\text { Longitudinal } \\
\text { Transtorno de } \\
\text { ansiedade }\end{array}$ & $\begin{array}{l}\text { Realizar uma } \\
\text { revisão sistemática } \\
\text { de estudos } \\
\text { longitudinais } \\
\text { olhando para o } \\
\text { resultado de } \\
\text { ansiedade na velhice }\end{array}$ & $\begin{array}{c}12 \\
\text { Estudos }\end{array}$ \\
\hline $\begin{array}{l}\text { Santa e } \\
\text { Cantilino. } \\
(2016) \\
\text { Brasil }\end{array}$ & $\begin{array}{l}\begin{array}{l}\text { Revisão } \\
\text { sistemática }\end{array} \\
\text { Tentativa de } \\
\text { suicido }\end{array}$ & $\begin{array}{l}\text { Construir uma } \\
\text { revisão integrativa } \\
\text { de literatura sobre o } \\
\text { suicídio em médicos } \\
\text { e estudantes de } \\
\text { Medicina com base } \\
\text { em uma análise de } \\
\text { artigos científicos } \\
\text { sobre o tema }\end{array}$ & $\begin{array}{c}17 \\
\text { Estudos }\end{array}$ \\
\hline
\end{tabular}

Refratariedade. associados com esses resultados são vários: Comprometimento episódios de humor, trauma e comorbidade funcional. psiquiátrica e clínica

Inflamação.

Aprendizado de

máquina.

Ansiedade.

Transtorno de

ansiedade.

Velhice.

Idoso.

Geriátrico.

Naturalista.

Longitudinal.

Saúde Mental.

Educação Médica.

Tentativa de

Suicídio.

Taxas de recaídas nos transtornos de

ansiedade altas ao longo dos 6 anos de acompanhamento, com considerável migração de episódios mistos de ansiedadedepressão e puro humor depressivo. Essa mistura parece ser estado de pior prognóstico

As taxas de suicídio nessa população são maiores do que as da população geral e de outros grupos acadêmicos. Causas de maior incidência de transtornos psiquiátricos, como depressão e abuso de substâncias, e sofrimento psíquico relacionados a vivências específicas da profissão, como grande carga de trabalho, privação do sono, dificuldade com pacientes, ambientes insalubres, preocupações financeiras e sobrecarga de informações

\begin{tabular}{|c|c|c|c|c|c|}
\hline $\begin{array}{l}\text { Stratford et } \\
\text { al. (2015) }\end{array}$ & $\begin{array}{l}\text { Transtorno } \\
\text { bipolar }\end{array}$ & $\begin{array}{l}\text { Analisar evidências } \\
\text { da eficácia da } \\
\text { terapia psicológica } \\
\text { para comorbilidade } \\
\text { de ansiedade em } \\
\text { adultos com } \\
\text { transtorno de } \\
\text { espectro bipolar }\end{array}$ & $\begin{array}{c}22 \\
\text { Estudos }\end{array}$ & $\begin{array}{l}\text { Transtorno bipolar. } \\
\text { Ansiedade. } \\
\text { Transtornos do } \\
\text { espectro bipolar. } \\
\text { Comorbidade de } \\
\text { ansiedade. } \\
\text { Terapia psicológica. } \\
\text { Terapia cognitivo- } \\
\text { comportamental. }\end{array}$ & $\begin{array}{l}\text { A terapia psicológica parece aceitável e } \\
\text { segura, mas a coleta e o relato mais } \\
\text { sistemáticos de informações de segurança e } \\
\text { aceitabilidade são necessários. } \\
\text { desenvolvimento de modelos psicológicos e } \\
\text { protocolos de tratamento para ansiedade em } \\
\text { BPSD pode ajudar a melhorar os resultados }\end{array}$ \\
\hline $\begin{array}{l}\text { Strejilevich } \\
\text { Samamé } \\
\text { e Martino. } \\
\text { (2015) } \\
\text { Irlanda do } \\
\text { Norte }\end{array}$ & $\begin{array}{l}\text { Longitudinal } \\
\text { Transtorno } \\
\text { bipolar. }\end{array}$ & $\begin{array}{l}\text { Examinar a } \\
\text { trajetória das } \\
\text { disfunções } \\
\text { neuropsicológicas } \\
\text { nos TB }\end{array}$ & $\begin{array}{c}12 \\
\text { Estudos }\end{array}$ & $\begin{array}{l}\text { Transtorno bipolar. } \\
\text { Conhecimento. } \\
\text { Disfunção cognitiva. } \\
\text { Estudos } \\
\text { Transversais. } \\
\text { Demência. }\end{array}$ & $\begin{array}{l}\text { Um risco aumentado de desenvolver } \\
\text { demência foi encontrado em indivíduos } \\
\text { bipolares. Evidência de estudos transversais } \\
\text { não mostraram déficits cognitivos mais } \\
\text { graves em pacientes com doença mais longa. } \\
\text { Além disso, estudos longitudinais revelaram } \\
\text { que o desempenho cognitivo de indivíduos } \\
\text { bipolares não mudou entre diferentes pontos } \\
\text { no tempo }\end{array}$ \\
\hline $\begin{array}{l}\text { Szmulewic } \\
\mathrm{z} \text { et al. } \\
\text { (2017) } \\
\text { Argentina }\end{array}$ & $\begin{array}{l}\text { Revisão } \\
\text { sistemática } \\
\text { Transtorno } \\
\text { depressivo } \\
\text { maior e } \\
\text { transtorno } \\
\text { bipolar. }\end{array}$ & $\begin{array}{l}\text { Fornecer uma } \\
\text { revisão sistemática } \\
\text { atualizada de } \\
\text { estudos comparando } \\
\text { o funcionamento } \\
\text { neuropsicológico } \\
\text { entre transtorno } \\
\text { bipolar e depressão } \\
\text { maior }\end{array}$ & $\begin{array}{c}50 \\
\text { Estudos }\end{array}$ & $\begin{array}{l}\text { Transtornos de } \\
\text { humor. } \\
\text { Transtornos } \\
\text { depressivos. } \\
\text { Transtorno bipolar. }\end{array}$ & $\begin{array}{l}\text { Sem diferenças significativas no } \\
\text { desempenho de atenção e velocidade de } \\
\text { processamento. Quanto à memória verbal } \\
\text { defeituoso desempenho para pacientes com } \\
\text { TDM }\end{array}$ \\
\hline
\end{tabular}

Fonte: Autores.

Dos 42 estudos selecionados, 24 artigos tratam de transtornos de humor predominantemente e 18 focalizaram aspectos relacionados enfaticamente a alterações neuropsicológicas. Dentre os transtornos de humor mais estudos, destacam-se o transtorno bipolar $(n=7)$, a depressão, com tentativa de suicídio $(n=6)$, o transtorno de ansiedade $(n=2)$, transtorno bipolar $(\mathrm{n}=1)$, transtorno depressivo maior $(\mathrm{n}=1)$, dentre os principais. Ganham destaques, estudos que valorizam o papel de sintomas importantes de transtornos mentais, tais como a impulsividade $(\mathrm{n}=2)$, a anedonia $(\mathrm{n}=2)$, a insegurança $(\mathrm{n}=1)$, a desesperança $(\mathrm{n}=1)$, afetividade $(\mathrm{n}=1)$. 
O transtorno bipolar foi o mais estudado, destacando-se: a) a existência de uma associação entre transtorno bipolar e depreciação do desempenho social, ocupacional e o do funcionamento cognitivo (Baune \& Malhi, 2015); b) pacientes melancólicos apresentam maiores déficits neuropsicológicos quando comparados com os não melancólicos e os pacientes hígidos, quando realizam em tarefas que requerem memória, função executiva, atenção e tempo de reação (Bosaipo et al., 2017); c) o declínio cognitivo está relacionado com o número de episódios de hospitalização e curso da doença (Cardoso et al., 2015); d) o transtorno bipolar do tipo 1 teve pior desempenho do que nos domínios Set-shifting, inibição, planejamento, fluência verbal, memória de trabalho e atenção. O transtorno bipolar do tipo 2 demonstrou prejuízo em fluência verbal, memória de trabalho, Set-shifting e atenção, logo pessoas com o tipo 2 podem experimentar prejuízo semelhante (ou às vezes maior) de funcionamento executivo (Dickinson et al., 2017); e) pacientes com transtorno bipolar apresentam um curso neuroprogressivo com mudanças cerebrais e resultados desfavoráveis. Os fatores de risco associados com esses resultados são vários: episódios de humor, trauma e comorbidade psiquiátrica e clínica (Passos et al., 2016); f) a terapia psicológica é vista como importante e segura, mas ainda é necessário estudos e relatos sistemáticos que demonstrem informações de sobre sua eficácia e aceitabilidade (Stratford et al., 2015); g) um risco aumentado de desenvolver demência foi encontrado em indivíduos bipolares (Strejilevich et al., 2015).

Dentre os estudos que investigaram o transtorno de humor associado ao suicídio/tentativas de suicídio, destacam-se os transtornos depressivos e demais comorbidades psicológicas e psiquiátricas; b) os fatores sociais associados à morte recente de familiares são referidos em 11,4\% dos estudos, assim como a participação de problemas financeiros e a falta de apoio familiar em $10,5 \%$ dos casos; c) os fatores clínicos como as doenças crônicas $(28,9 \%)$, dores crônicas $(7,8 \%)$ e o comprometimento funcional (2,6\%) também pesam para as pessoas que cometem suicídio (Bortolini, 2016); d) os fatores externos associados às causas prevalentes para a ideia de suicídio são: o abuso de drogas lícitas e ilícitas, pressão escolar e conflitos familiares, fatores internos como saúde mental debilitada e depressão (Miranda et al., 2018); e) o suicídio ocorrem com maior incidência em pessoas com transtornos mentais (especialmente depressão), associados ao abuso de substâncias psicoativas; f) o sofrimento psíquico relatado estão associados a problemas profissionais, sobrecarga de trabalho/informações, privação do sono, problemas de relacionamento, preocupações financeiras (Santa \& Cantilino, 2016).

O transtorno depressivo e o transtorno depressivo maior foram evidenciados nos estudos investigados: a) nesses casos, os déficits cognitivos estão associados à disfunção na esfera psicossocial - perda de qualidade de vida e no funcionamento social, ocupacional e global. A idade mais avançada e a maior gravidade dos sintomas de transtorno depressivo maior parecem aumentar a relação cognição-disfunção psicossocial (Cambridge et al., 2018); b) O Inventário de Depressão de Beck (BDI-II) é comumente utilizado para auxiliar no diagnóstico desses transtornos, pode ser aplicado tanto em idosos saudáveis, quanto em idosos de grupos clínicos. Os grupos clínicos são compostos por idosos com depressão, doença de Parkinson, Alzheimer, declínio cognitivo leve, distúrbio de sono e esclerose múltipla (Argimon et al., 2016); c) os serviços de assistências mais comuns em mulheres com depressão são: escuta qualificada, musicoterapia, terapia cognitiva comportamental, biodança e auxílio na terapia medicamentoso (Gomes \& Ivo, 2017).

Ao investigar a combinação dos transtornos de ansiedade e depressão em mulheres grávidas, Kliemann et al. (2017) apontaram que os fatores socioeconômicos, o histórico de saúde mental, as complicações obstétricas e a rede de apoio frágil são os principais fatores de risco aos agravos à saúde mental. Na combinação do transtorno depressivo maior e do transtorno bipolar, os autores concluíram não haver diferenças significativas no desempenho de atenção e velocidade de processamento. Quanto à memória verbal defeituosa, o desempenho é visto para pacientes com transtorno de depressão maior (Szmulewicz et al., 2017).

Destaca-se como achados de pesquisa nos artigos que tratam sobre anedonia, transtorno de ansiedade e impulsividade as seguintes ponderações: a) as funções executivas, a memória emocional e a motivação para agir são afetados manifestam-se, 
especialmente, em pessoas com esquizofrenia (Edwards et al., 2015); b) a maioria dos medicamentos antidepressivos respondem favoravelmente na amenização dos sintomas da anedonia e depressivos (Cao et al., 2019); c) as taxas de recaídas nos transtornos de ansiedade são altas. No estudo de Sami et al. (2015), ao longo de 6 anos de acompanhamento, houve uma considerável migração de episódios mistos de ansiedade-depressão e humor depressivo, sendo isso considerado um prognóstico desfavorável; d) as correlações significativas entre cada faceta da impulsividade e a agressão em suas várias formas diferentes, revelam que com mais impulsividade, há mais agressão. As urgências negativa e positiva, assim como a falta de premeditação, apresentaram associação significativamente mais fortes com agressão (Bresin, 2019); d) na associação da impulsividade com a automutilação ou comportamento suicida, não houve diferenças significativas entre as medidas das diferentes facetas (McHugh et al., 2019). No estudo de Gibson et al. (2018) nota-se que as cicatrizes faciais podem ter um efeito dramático na saúde psicológica e no bem-estar do paciente, pois há uma alta carga de transtornos afetivos. Entretanto, esta associação pode diminuir gradualmente com o tempo. As mulheres, a história psiquiátrica pregressa e a causalidade violenta tendem a ser associadas ao aumento da prevalência de ansiedade e depressão.

Sobre a desesperança, pondera-se nos achados de pesquisa de Júnior et al. (2018) que ela esteve presente em idosos mais suscetíveis a problemas físicos, emocionais e fragilidade cognitiva. Por isso é importante a adoção de uma abordagem holística para os idosos, no intuito de identificar vários sintomas e eventos que levam ao aumento da desesperança. Karantzas, Romano e Lee (2019) pontuam que o papel do apego no cuidado da velhice ainda é algo que necessita ser desvendado, isso porque é por meio do estudo do apego que pode se examinar o cuidado familiar com os idosos, bem como a insegurança que eles sentem em relação a sua própria longevidade. Para o cuidador, a ansiedade do apego foi associada a uma pior saúde mental e a insegurança do apego a uma forma mais controladora de cuidar. Nesse sentido, há indícios de que a insegurança de apego tende a estar associada a uma maior autoavaliação dos sintomas de demência e a uma menor sensação de segurança.

Tabela 2. Informações dos estudos selecionados sobre alterações neuropsicológicas em termos de autores, tipo de estudo, objetivo, amostra, palavras-chaves e resultados.

\begin{tabular}{|c|c|c|c|c|c|}
\hline Autores & $\begin{array}{c}\text { Tipo estudo e } \\
\text { Alteração } \\
\text { Neuropsicológica }\end{array}$ & Objetivo & Amostra & Palavras-Chaves & Resultados \\
\hline $\begin{array}{l}\text { Arent et al. } \\
(2019) \\
\text { Brasil }\end{array}$ & $\begin{array}{l}\text { Revisão sistemática } \\
\text { Esclerose Múltipla }\end{array}$ & $\begin{array}{l}\text { Identificar e } \\
\text { discutir os } \\
\text { instrumentos de } \\
\text { avaliação } \\
\text { neuropsicológica } \\
\text { utilizados } \\
\text { atualmente com } \\
\text { pessoas com } \\
\text { diagnóstico de } \\
\text { EM }\end{array}$ & $\begin{array}{c}58 \\
\text { Estudos }\end{array}$ & $\begin{array}{l}\text { Esclerose Múltipla. } \\
\text { Avaliação } \\
\text { neuropsicológica. } \\
\text { Testes. } \\
\text { Revisão sistemática. }\end{array}$ & $\begin{array}{l}\text { As baterias breves mais utilizadas são: Brief } \\
\text { International Cognitive Assessment of } \\
\text { Multiple Sclerosis (BICAMS), Multiple } \\
\text { Sclerosis Functional Composite Measure } \\
\text { (MSFC) e Brief Repeatable Battery of } \\
\text { Neuropsychological Test (BNB-N). Os testes } \\
\text { mais utilizados na avaliação neuropsicológica } \\
\text { de paciente com EM são PASAT e SDMT, que } \\
\text { enfocam a avaliação da velocidade de } \\
\text { processamento e memória operacional }\end{array}$ \\
\hline $\begin{array}{l}\text { Barboza e } \\
\text { Barbosa e } \\
\text { Fichman. } \\
\text { (2019) } \\
\text { Brasil }\end{array}$ & $\begin{array}{l}\text { Revisão sistemática } \\
\text { Doença de } \\
\text { Parkinson (DP) }\end{array}$ & $\begin{array}{l}\text { Analisar o } \\
\text { impacto no } \\
\text { funcionamento } \\
\text { cognitivo de } \\
\text { pacientes com DP }\end{array}$ & $\begin{array}{c}27 \\
\text { Estudos }\end{array}$ & $\begin{array}{l}\text { Doença de Parkinson. } \\
\text { Estimulação cerebral } \\
\text { profunda. } \\
\text { Núcleo subtalâmico, } \\
\text { Cognição. }\end{array}$ & $\begin{array}{l}\text { Revelou resultados conflitantes, impedindo um } \\
\text { consenso sobre um padrão de funcionamento } \\
\text { cognitivo e dificultando o estabelecimento de } \\
\text { um perfil neuropsicológico para pacientes com } \\
\text { DP }\end{array}$ \\
\hline $\begin{array}{l}\text { Belleville et al. } \\
\text { (2017) } \\
\text { Canadá }\end{array}$ & $\begin{array}{l}\text { Revisão sistemática } \\
\text { e meta-análise } \\
\text { Demência tipo } \\
\text { Alzheimer }\end{array}$ & $\begin{array}{l}\text { Avaliar a precisão } \\
\text { preditiva de } \\
\text { diferentes } \\
\text { categorias de } \\
\text { domínio cognitivo } \\
\text { e determinar se a } \\
\text { precisão varia em } \\
\text { função da idade e }\end{array}$ & $\begin{array}{c}28 \\
\text { Estudos }\end{array}$ & $\begin{array}{l}\text { Doença de Alzheimer. } \\
\text { Comprometimento } \\
\text { cognitivo leve. } \\
\text { Neuropsicologia. } \\
\text { Diagnóstico. } \\
\text { Testes cognitivos. } \\
\text { Preditivo. } \\
\text { Precisão. }\end{array}$ & $\begin{array}{l}\text { Muitos domínios apresentaram acurácia } \\
\text { preditiva muito boa, com valores elevados de } \\
\text { sensibilidade e especificidade }(\geq 0,7) \text {. Memória } \\
\text { verbal e testes de idioma produziram uma } \\
\text { precisão preditiva muito alta. Os testes } \\
\text { cognitivos são excelentes para prever } \\
\text { indivíduos com CGL que irão progredir para } \\
\text { demência }\end{array}$ \\
\hline
\end{tabular}

do tempo de

acompanhamento 
Research, Society and Development, v. 11, n. 2, e37211225566, 2022

(CC BY 4.0) | ISSN 2525-3409 | DOI: http://dx.doi.org/10.33448/rsd-v11i2.25566

\begin{tabular}{|c|c|c|c|c|c|}
\hline $\begin{array}{l}\text { Bernardo. } \\
\text { (2018) } \\
\text { Brasil }\end{array}$ & $\begin{array}{l}\text { Revisão sistemática } \\
\text { intervenção } \\
\text { Doença de } \\
\text { Alzheimer }\end{array}$ & $\begin{array}{l}\text { Identificar e } \\
\text { analisar a } \\
\text { produção } \\
\text { científica da } \\
\text { intervenção do } \\
\text { Terapeuta } \\
\text { Ocupacional no } \\
\text { cuidado ao idoso } \\
\text { com doença de } \\
\text { Alzheimer que } \\
\text { apresenta } \\
\text { alterações }\end{array}$ & $\begin{array}{c}13 \\
\text { Estudos }\end{array}$ & $\begin{array}{l}\text { Terapia Ocupacional. } \\
\text { Doença de Alzheimer. } \\
\text { Idoso. } \\
\text { Terapêutica. } \\
\text { Atividades Científicas } \\
\text { e Técnicas. }\end{array}$ & $\begin{array}{l}\text { As intervenções identificadas são direcionadas } \\
\text { à regulação emocional, habilidades motoras e } \\
\text { habilidades processuais. O terapeuta usa ajuda } \\
\text { externa, atividades de computador e } \\
\text { estimulação multisetorial como recursos para } \\
\text { aprendizagem motora, orientação espacial para } \\
\text { mudança do comportamento }\end{array}$ \\
\hline $\begin{array}{l}\text { Brunt, } \\
\text { Albines e } \\
\text { Hopkins- } \\
\text { Rosseel. (2019) } \\
\text { Canadá }\end{array}$ & $\begin{array}{l}\text { Revisão sistemática } \\
\text { Doenças vasculares } \\
\text { e cardiovasculares }\end{array}$ & $\begin{array}{l}\text { Entender o } \\
\text { exercício como } \\
\text { uma modalidade } \\
\text { para melhorar } \\
\text { cognição em } \\
\text { pessoas com } \\
\text { doença vascular, } \\
\text { com foco nas } \\
\text { respostas à dose }\end{array}$ & $\begin{array}{c}22 \\
\text { Estudos }\end{array}$ & $\begin{array}{l}\text { Doença } \\
\text { cardiovascular. } \\
\text { Doença cardíaca. } \\
\text { Doença vascular. } \\
\text { Derrame. } \\
\text { Ataque isquêmico } \\
\text { transitório. } \\
\text { Exercício. } \\
\text { Técnica de } \\
\text { movimento do } \\
\text { exercício. } \\
\text { Esportes. } \\
\text { Conhecimento. } \\
\text { Consciência. } \\
\end{array}$ & $\begin{array}{l}\text { O exercício é capaz de afetar positivamente o } \\
\text { desempenho cognitivo em pessoas com doença } \\
\text { vascular conhecida. Há evidências que } \\
\text { sugerem uma relação dose-resposta. Mais } \\
\text { pesquisas são necessárias para otimizar a } \\
\text { prescrição }\end{array}$ \\
\hline $\begin{array}{l}\text { Cromarty et al. } \\
\text { (2016) } \\
\text { Inglaterra }\end{array}$ & $\begin{array}{l}\text { Revisão sistemática } \\
\text { Demências por } \\
\text { corpos de Lewy }\end{array}$ & $\begin{array}{l}\text { Identificar } \\
\text { potenciais } \\
\text { biomarcadores } \\
\text { neurofisiológicos } \\
\text { nos Demência } \\
\text { com Corpo de } \\
\text { Lewy }\end{array}$ & $\begin{array}{c}37 \\
\text { Estudos }\end{array}$ & $\begin{array}{l}\text { Biomarcadores. } \\
\text { Demência com corpos } \\
\text { de Lewy. } \\
\text { Doença de Parkinson } \\
\text { com demência. } \\
\text { Flutuações cognitivas. } \\
\text { Neurofisiologia. }\end{array}$ & $\begin{array}{l}\text { Geralmente, muitos dos achados ainda } \\
\text { precisam ser replicados, embora os achados } \\
\text { preliminares reforcem a utilidade potencial de } \\
\text { abordagens como a eletroencefalografia } \\
\text { quantitativa e os paradigmas de estimulação } \\
\text { cortical motora }\end{array}$ \\
\hline $\begin{array}{l}\text { Combs et al. } \\
(2015) \\
\text { EUA }\end{array}$ & $\begin{array}{l}\text { Meta-análise } \\
\text { Doença de } \\
\text { Parkinson }\end{array}$ & $\begin{array}{l}\text { Determinar se } \\
\text { potenciais } \\
\text { deficiências } \\
\text { cognitivas são } \\
\text { artefatos em vez } \\
\text { de efeitos reais. }\end{array}$ & $\begin{array}{c}38 \\
\text { Estudos }\end{array}$ & $\begin{array}{l}\text { Doença de Parkinson. } \\
\text { Estimulação cerebral } \\
\text { profunda. }\end{array}$ & $\begin{array}{l}\text { Foram encontrados prejuízos na velocidade } \\
\text { psicomotora, memória, atenção e funções } \\
\text { executivas e cognição geral, declínio moderado } \\
\text { foram achados na fluência semântica e fonética }\end{array}$ \\
\hline $\begin{array}{l}\text { das Nair, } \\
\text { Martin e } \\
\text { Lincoln. (2016) } \\
\text { França }\end{array}$ & $\begin{array}{l}\text { Intervenção } \\
\text { Esclerose múltipla. }\end{array}$ & $\begin{array}{l}\text { Determinar se as } \\
\text { pessoas com EM } \\
\text { que receberam } \\
\text { reabilitação de } \\
\text { memória } \\
\text { mostraram } \\
\text { melhorias em } \\
\text { comparação com } \\
\text { os que não } \\
\text { receberam } \\
\text { tratamento }\end{array}$ & $\begin{array}{c}15 \\
\text { Estudos }\end{array}$ & $\begin{array}{l}\text { Reabilitação da } \\
\text { memória. } \\
\text { Esclerose múltipla. }\end{array}$ & $\begin{array}{l}\text { Os achados revelaram efeitos significativos da } \\
\text { intervenção na avaliação da memória imediata } \\
\text { e a longo prazo. Efeitos significativos também } \\
\text { foram encontrados na intervenção de qualidade } \\
\text { de vida no seguimento imediato, que o grupo } \\
\text { de intervenção teve melhor desempenho. Não } \\
\text { foram observadas diferenças significativas } \\
\text { entre a memória e humor imediato tanto quanto } \\
\text { a longo prazo }\end{array}$ \\
\hline $\begin{array}{l}\text { Dinkelbach et } \\
\text { al. (2017) } \\
\text { Alemanha }\end{array}$ & $\begin{array}{l}\text { Revisão sistemática } \\
\text { Doença de } \\
\text { Parkinson }\end{array}$ & $\begin{array}{l}\text { Estudar } \\
\text { estimulação } \\
\text { cerebral não } \\
\text { invasiva da } \\
\text { cognição e humor } \\
\text { não na doença de } \\
\text { Parkinson }\end{array}$ & $\begin{array}{c}19 \\
\text { Estudos }\end{array}$ & $\begin{array}{l}\text { Cognição. } \\
\text { Depressão. } \\
\text { Demência. } \\
\text { Estimulação cerebral } \\
\text { não invasiva (ECnI). } \\
\text { Doença de Parkinson } \\
\text { (DP). } \\
\text { Estimulação } \\
\text { magnética } \\
\text { transcraniana } \\
\text { repetitiva (EMTr). } \\
\text { Estimulação } \\
\text { transcraniana por } \\
\text { corrente contínua. }\end{array}$ & $\begin{array}{l}\text { Os resultados dependeram da área estimulada e } \\
\text { da técnica usada. Quando usar estimulação } \\
\text { magnética transcraniana repetitiva sobre o } \\
\text { córtex dorsolateral pré-frontal, observa-se } \\
\text { redução significativa nos sintomas depressivos } \\
\text { de moderado a grande e aumento de } \\
\text { desempenho nos testes cognitivos }\end{array}$ \\
\hline
\end{tabular}


Research, Society and Development, v. 11, n. 2, e37211225566, 2022

(CC BY 4.0) | ISSN 2525-3409 | DOI: http://dx.doi.org/10.33448/rsd-v11i2.25566

\begin{tabular}{|c|c|c|c|c|}
\hline $\begin{array}{l}\text { Fernandes, } \\
\text { Esper e } \\
\text { Faiman. (2017) } \\
\text { Brasil }\end{array}$ & $\begin{array}{l}\text { Revisão sistemática } \\
\text { Esquizofrenia }\end{array}$ & $\begin{array}{l}\text { Levantar estudos } \\
\text { na literatura que } \\
\text { tragam } \\
\text { informações } \\
\text { acerca do paciente } \\
\text { portador de } \\
\text { esquizofrenia e } \\
\text { direção veicular, } \\
\text { buscando } \\
\text { responder se } \\
\text { podem ou não ser } \\
\text { liberados através } \\
\text { do exame } \\
\text { mental/psicológic }\end{array}$ & $\begin{array}{c}13 \\
\text { Estudos }\end{array}$ & $\begin{array}{l}\text { Esquizofrenia. } \\
\text { Condução de Veículo. }\end{array}$ \\
\hline
\end{tabular}

Existem estudos que sugerem um maior número de infrações às regras de trânsito e acidentes de viação em pacientes esquizofrênicos. Esquizofrênicos que dirigiam apresentaram-se melhores no exame do estado mental que esquizofrênicos não motoristas. As taxas de acidente encontradas foram quase idênticas nos grupos de pacientes com transtornos psicóticos e controle, e que além disso, taxas de acidentes com lesões podem ser equiparadas com as da população geral

ntal/psicologic

\begin{tabular}{ll}
\hline Harrison et al. & Validade interna e \\
(2016) & externa \\
Inglaterra & Demência
\end{tabular}

Descrever as $805 \quad$ Demência.

Identificamos heterogeneidade significativa

medidas de Estudos Cognição.

desfecho Qualidade de vida.

Humor. nas ferramentas utilizadas para capturar esses

utilizadas em

Comportamento resultados, com uso frequente de testes não

estudos de

Centrado no Paciente. padronizados

intervenção de

demência e

comprometimento

cognitivo leve,

que avaliam

desempenho

funcional e

qualidade de vida

no paciente

\begin{tabular}{ll}
\hline Johnen et al. & Meta-análise \\
$(2017)$ & Esclerose múltipla \\
EUA &
\end{tabular}

Compreender

47 Disfunção cognitiva.

magnitude e perfil Estudos

Demência. Humanos.

do

Testes

comprometimento

neuropsicológicos.

cognitivo com

Avaliação de

testes psicológicos

Resultados (Cuidados

padronizados em

de Saúde).

Diagnóstico.

esclerose múltipla

Epidemiologia.

Apontam para o comprometimento grave em geral em cada domínio cognitivo em pacientes EMPP apesar dos graus comparáveis de fadiga e depressão, se viu também as diferenças não eram atribuíveis a curso da doença e foram claras as diferenças entre ESPP e ESRR quanto a memória em particular a verbal

primária EMPP e

EMRR.

\begin{tabular}{|c|c|c|c|c|c|}
\hline $\begin{array}{l}\text { Kar, Whitehead } \\
\text { e Smith. (2017) } \\
\text { Inglaterra }\end{array}$ & $\begin{array}{l}\text { Revisão sistemática } \\
\text { Esclerose múltipla }\end{array}$ & $\begin{array}{l}\text { Examinar as } \\
\text { estratégias de } \\
\text { enfrentamento que } \\
\text { as pessoas com } \\
\text { esclerose múltipla } \\
\text { usam e identificar } \\
\text { os fatores que } \\
\text { influenciam seu } \\
\text { padrão de } \\
\text { enfrentamento }\end{array}$ & $\begin{array}{c}38 \\
\text { Estudos }\end{array}$ & $\begin{array}{l}\text { Lidar. } \\
\text { Esclerose múltipla. } \\
\text { Revisão sistemática. }\end{array}$ & $\begin{array}{l}\text { A síntese das descobertas indicou que as } \\
\text { pessoas com esclerose múltipla usam } \\
\text { estratégias de enfrentamento emocionais e de } \\
\text { evitação mais do que outros tipos de } \\
\text { enfrentamento, principalmente nos estágios } \\
\text { iniciais da doença. O padrão de enfrentamento } \\
\text { foi associado a fatores individuais, clínicos e } \\
\text { psicológicos, incluindo gênero, nível } \\
\text { educacional, curso clínico, humor e estado } \\
\text { mental, atitude, traços de personalidade e } \\
\text { crenças religiosas }\end{array}$ \\
\hline $\begin{array}{l}\text { Mitolo et } \\
\text { al.(2015) } \\
\text { Inglaterra. }\end{array}$ & $\begin{array}{l}\text { Intervenção } \\
\text { Esclerose múltipla }\end{array}$ & $\begin{array}{l}\text { Realizar uma } \\
\text { revisão } \\
\text { sistemática } \\
\text { atualizada de } \\
\text { todos os estudos } \\
\text { publicados de } \\
\text { intervenções de } \\
\text { reabilitação } \\
\text { cognitiva em } \\
\text { pessoas com EM }\end{array}$ & $\begin{array}{c}33 \\
\text { Estudos }\end{array}$ & $\begin{array}{l}\text { Reabilitação } \\
\text { cognitiva. } \\
\text { Esclerose Múltipla. } \\
\text { Atenção. } \\
\text { Memória de trabalho. } \\
\text { Qualidade de vida. }\end{array}$ & $\begin{array}{l}\text { Resultados indicam não haver conclusão } \\
\text { definitiva acerca de efeito em diferentes tipos } \\
\text { de intervenções na reabilitação cognitiva } \\
\text { nesses indivíduos }\end{array}$ \\
\hline $\begin{array}{l}\text { Mondragón, } \\
\text { Maurits e } \\
\text { De Deyn } \\
\text { (2019) }\end{array}$ & $\begin{array}{l}\text { Revisão sistemática } \\
\text { Doença Alzheimer }\end{array}$ & $\begin{array}{l}\text { Fornecer } \\
\text { compreensão do } \\
\text { processamento } \\
\text { autorreferencial } \\
\text { de anosognosia }\end{array}$ & $\begin{array}{c}25 \\
\text { Estudos }\end{array}$ & $\begin{array}{l}\text { Alzheimer. } \\
\text { Anosognosia. } \\
\text { Conectividade. } \\
\text { Metabolismo. } \\
\text { Perfusão. }\end{array}$ & $\begin{array}{l}\text { A conectividade reduzida entre rede é } \\
\text { observada nas regiões da rede no modo padrão } \\
\text { nos pacientes com DA com anosognosia em } \\
\text { comparação com pacientes com e sem DA. O } \\
\text { estágio inicial de declínio cognitivo na }\end{array}$ \\
\hline
\end{tabular}




\begin{tabular}{|c|c|c|c|c|c|}
\hline Holanda & & em CGL e DA. & & $\begin{array}{l}\text { Comprometimento } \\
\text { cognitivo leve. }\end{array}$ & $\begin{array}{l}\text { anosognosia, a redução da atividade neural } \\
\text { indireta está associada às regiões da linha } \\
\text { média cortical, estrutura parietotemporal em } \\
\text { estágios posteriores e finaliza na disfunção } \\
\text { frontotemporal }\end{array}$ \\
\hline $\begin{array}{l}\text { Newton, } \\
\text { Naiberg e } \\
\text { Goldstein. } \\
\text { (2015) } \\
\text { Canadá }\end{array}$ & $\begin{array}{l}\text { Revisão sistemática } \\
\text { Demência e AVC. }\end{array}$ & $\begin{array}{l}\text { examinar a } \\
\text { literatura atual } \\
\text { sobre estresse } \\
\text { oxidativo e } \\
\text { cognição em } \\
\text { indivíduos sem } \\
\text { acidente vascular } \\
\text { cerebral, } \\
\text { neurodegeneração } \\
\text { AVC e / ou DA } \\
\text { AVA }\end{array}$ & $\begin{array}{c}19 \\
\text { Estudos }\end{array}$ & $\begin{array}{l}\text { Revisão sistemática. } \\
\text { Função executiva. } \\
\text { Antioxidantes. } \\
\text { Peroxidação lipídica. } \\
\text { Distúrbios } \\
\text { psiquiátricos. }\end{array}$ & $\begin{array}{l}\text { Funções cognitivas frontais estão } \\
\text { frequentemente prejudicadas, memória e } \\
\text { função cognitiva geral era menos robusta, } \\
\text { população psiquiátrica é a mais afetada. A } \\
\text { disfunção frontal-executiva implica regiões } \\
\text { frontais do cérebro }\end{array}$ \\
\hline $\begin{array}{l}\text { Tucker e } \\
\text { Bertke. } \\
\text { (2019) } \\
\text { EUA }\end{array}$ & $\begin{array}{l}\text { Revisão sistemática } \\
\text { e meta-análise } \\
\text { Esquizofrenia e } \\
\text { transtorno bipolar. }\end{array}$ & $\begin{array}{l}\text { Analisar os dados } \\
\text { agregados de } \\
\text { testes } \\
\text { neuropsicológicos } \\
\text { de estudos } \\
\text { anteriores sobre o } \\
\text { impacto da } \\
\text { infecção por } \\
\text { HSV-1 na função } \\
\text { cognitiva na } \\
\text { esquizofrenia e no } \\
\text { transtorno bipolar }\end{array}$ & $\begin{array}{c}12 \\
\text { Estudos }\end{array}$ & $\begin{array}{l}\text { Memória. } \\
\text { Atenção. } \\
\text { Conhecimento. } \\
\text { Distúrbios } \\
\text { psiquiátricos. }\end{array}$ & $\begin{array}{l}\text { Um efeito geral estatisticamente significativo } \\
\text { de comprometimento cognitivo para os índices } \\
\text { de memória e atenção foi a favor de pacientes } \\
\text { com esquizofrenia positiva para HIV. infecção } \\
\text { por HIV têm um impacto significativo na } \\
\text { função cognitiva de pequeno a moderado. } \\
\text { Afetando a memória e a atenção, em } \\
\text { esquizofrenia e pacientes bipolares }\end{array}$ \\
\hline $\begin{array}{l}\text { Wojcik et al. } \\
(2019) \\
E U A\end{array}$ & $\begin{array}{l}\text { Revisão sistemática } \\
\text { Esclerose Múltipla }\end{array}$ & $\begin{array}{l}\text { Identificar } \\
\text { baterias de teste e } \\
\text { testes únicos com } \\
\text { boas evidências de } \\
\text { confiabilidade e } \\
\text { validade, nos } \\
\text { dispositivos } \\
\text { computadorizados } \\
\text { de avaliação } \\
\text { neuropsicológica } \\
\text { (DCAN) }\end{array}$ & $\begin{array}{c}51 \\
\text { Estudos }\end{array}$ & $\begin{array}{l}\text { Esclerose múltipla. } \\
\text { Testes } \\
\text { computadorizados. } \\
\text { Cognição. } \\
\text { Revisão sistemática. } \\
\text { Confiabilidade. } \\
\text { Validade. }\end{array}$ & $\begin{array}{l}\text { DCAN com suporte mais forte incluem a } \\
\text { CogState Brief Battery, Bateria de pesquisa de } \\
\text { drogas cognitivas, NeuroTrax, CNS-Vital } \\
\text { Signs e administrações baseadas em } \\
\text { computador do Teste de Modalidades de } \\
\text { Símbolo Dígito }\end{array}$ \\
\hline
\end{tabular}

Fonte: Autores.

Em 18 estudos investigados, o foco foi nos aspectos relacionados aos transtornos de humor em pacientes com alterações neuropsicológicas, tais como, esclerose múltipla $(n=6)$, demência $(n=4)$, doença de Parkinson $(n=3)$, doença de Alzheimer $(n=2)$, esquizofrenia $(n=2)$, doença vascular e cardiovascular $(n=1)$.

No que tange à esclerose múltipla, os achados dos estudos encontrados indicam que: a) os testes mais utilizados na avaliação neuropsicológica de pacientes com esclerose múltipla são Paced Auditory Serial Addition Test (PASAT) e Symbol Digit Modalities Test (SDMT), nos quais avaliam, entre outras funções cognitivas, a velocidade de processamento da informação e da memória operacional (Arent et al., 2019); b) as intervenções em pacientes com esclerose múltipla envolveram várias técnicas de retreinamento da memória, como programas computadorizados e treinamento em ajudas de memória interna e externa. Isso ocasionou efeitos significativos na memória imediata e de longo prazo, qualidade de vida imediata e de longo prazo e atividades da vida diária, porém a evidência é limitada e não se estende a relatos subjetivos de funcionamento da memória ou humor (Nair et al., 2016); c) na comparação da magnitude e do perfil do comprometimento cognitivo em pacientes com Esclerose Múltipla Progressiva Primária contra a Esclerose Múltipla Recorrente-Remitente, medido com testes neuropsicológicos padronizados, os resultados mostraram que o primeiro grupo de pacientes apresentaram graus mais graves de comprometimento cognitivo e precisaram de tratamento mais especializado do que os pacientes do segundo grupo de doença (Johnen et al., 2017). 
Em síntese, as descobertas no estudo de Kar et al. (2017) indicam que as pessoas com esclerose múltipla usam estratégias de enfrentamento emocionais e de evitação mais do que outros tipos de enfrentamento, principalmente nos estágios iniciais da doença. O padrão de enfrentamento foi associado a fatores individuais, clínicos e psicológicos, incluindo gênero, nível educacional, curso clínico, humor e estado mental, atitude, traços de personalidade e crenças religiosas. E, os resultados indicam não haver conclusão definitiva acerca do efeito em diferentes tipos de intervenções na reabilitação cognitiva nesses indivíduos (Mitolo et al., 2015).

Os testes computadorizados podem facilitar a identificação de déficits prodrômicos, capturando diferenças mínimas no tempo de resposta não identificadas pelos testes tradicionais. Destaca-se alguns testes que possuem qualidades psicométricas e servem como ferramentas de triagem úteis ou suplementos para avaliações completas de esclerose múltiplas: subtestes do Bateria de Pesquisa de Drogas Cognitivas (CDR), CogState Brief Battery (CBB), Teste de Velocidade de Processamento de Informação NeuroTrax, Sistema Nervoso Central - Sinais Vitais (CNSVS), Teste Computadorizado de Modalidades de Símbolos e Dígitos (C-SDMT), Teste de Velocidade de Processamento (PST) e Teste Cognitivo de Velocidade Computadorizado (CSCT) (Wojcik et al., 2019).

Ao analisar os transtornos de humor em pacientes com alterações neuropsicológicas decorrente da demência, observase alguns levantamentos importantes: a) a avaliação neuropsicológica, pode contribuir fortemente para prever a demência enquanto os indivíduos ainda estão na fase de comprometimento cognitivo leve. Os testes cognitivos (Guild Paragraph delayed recall, RAVLT - delayed Recall, Face-name association task, free delayed recall of names, Object function recognition, VOSP Silhouettes e ACE Addenbrooke's Cognitive Examination) podem prever se os pacientes com comprometimento cognitivo leve irão progredir para demência pelo menos 3 anos antes do momento em que o diagnóstico é feito e contribui também para o desenvolvimento de índices iniciais da doença de Alzheimer (Belleville et al., 2017); b) é importante identificar biomarcadores neurofisiológicos em pacientes com demência com corpos de Lewy (DCL), a fim de compreender e acompanhar a sua progressão, agilizar o diagnóstico precoce e permitir a obtenção de um diagnóstico diferencial, em específico, durante a fase prodrômica da doença, assim, é possível estabelecer protocolos de monitorar com precisão a resposta terapêutica ao tratamento, e, em última análise, desenvolver intervenções modificadoras da doença precoce (Cromarty et al., 2016); c) a padronização de relatórios de avaliação da demência necessita ser padronizado no campo, que tem maior potencial para o benefício do paciente, facilitando a comparação dos resultados e evitando relatórios pouco claros e heterogeneidade de medidas (Harrison et al., 2016); d) o estresse oxidativo tem sido implicado em déficits cognitivos em estados de doença, como demência e acidente vascular cerebral. Nesse sentido, as funções cognitivas frontais foram identificadas como as mais frequentemente prejudicadas, e a peroxidação lipídica como as mais comumente associadas à essas deficiências, segundo o levantamento de revisão bibliográfica feito por (Newton et al., 2015).

Quanto às alterações neuropsicológicas decorrentes da doença de Alzheimer, enfatizam-se os achados: a) as mudanças comportamentais em idosos com doença de Alzheimer ocasiona impacto emocional e compromete a qualidade de vida deles e do cuidador. Nesse sentido, as intervenções de terapeutas ocupacionais identificadas foram direcionadas à regulação emocional, habilidades motoras e processuais, no intuito de atestar o efeito das intervenções no aprendizado motor, na orientação no espaço ou na diminuição dos sintomas neuropsicológicos e/ou das alterações comportamentais (Bernardo, 2018); b) os correlatos neurais de anosognosia e desconhecimento de déficits de memória em pacientes com comprometimento cognitivo leve e doença de Alzheimer diferem dependendo da técnica de imagem. Em pacientes com doença de Alzheimer, a conectividade funcional dentro da rede atenuada está associada ao declínio da percepção dos déficits de memória na rede do córtex temporal médio lateral (Mondragón et al., 2019). Diante disso, salienta-se que nos estudos apresentados ainda não está claro a associação entre os déficits de memória e a interrupção das regiões cerebrais envolvidas na memória, por isso é necessário estudos estruturados que consigam explorar essa dimensão. 
Sobre a esquizofrenia, pondera-se os principais achados: a) pacientes com esquizofrenia tendem a cometer um maior número de infrações às regras de trânsito e acidentes de viação. As taxas de acidente encontradas foram quase idênticas nos grupos de pacientes com transtornos psicóticos e controle, e que além disso, taxas de acidentes com lesões podem ser equiparadas com as da população geral (Fernandes et al., 2017); b) um efeito geral estatisticamente significativo de comprometimento cognitivo para os índices de memória e atenção foi em pacientes com esquizofrenia e Human Immunodeficiency Virus (HIV), ou seja, a infecção por HIV têm um impacto significativo na função cognitiva de pequeno a moderado, afetando a memória e a atenção, em esquizofrenia e pacientes bipolares (Tucker \& Bertke, 2019). Em suma, os pacientes com esquizofrenia apresentam quadros clínicos extremamente heterogêneos, somados às suas comorbidades, exercendo distinta influência no funcionamento cognitivo e psicomotor. Porém, os estudos traçados não permitiram exercer com solidez a aferição destas perdas mentais, por isso torna-se de extrema importância a investigação mais apurada destes pacientes, para que possam desenvolver papéis sociais com qualidade de vida.

Os principais achados relacionados à doença vascular e cardiovascular envolvem a prática de exercício físico, que pode afetar positivamente tanto o coração quanto as estruturas cerebrais. Isso porque os efeitos do exercício, provavelmente, são oriundos do aumento do fluxo sanguíneo cerebral e, por conseguinte, do aporte de nutrientes. Paralelamente, há evidências de que o efeito agudo do exercício físico possa ser mediado por um aumento na atividade de neurotransmissores, portanto, especula-se que o exercício pode promover adaptações em estruturas cerebrais e na plasticidade sináptica que resultam em melhoras cognitivas, entretanto, são necessárias mais pesquisas que estabeleçam essa relação (Brunt et al., 2019).

\section{Considerações Finais}

A revisão sistemática deste estudo permitiu identificar, no período de 2015 a 2019, as contribuições dos artigos publicados relacionados aos transtornos de humor em pacientes com alterações neuropsicológicas. A nível continental, a América apresentou o maior quantitativo de produções nos seguintes países: Brasil, Estados Unidos, Argentina e Canadá. Uma representatividade deveras pequena, já que a América é composta por 35 países. Do mesmo modo ocorre com a representatividade dos continentes Europeu (Inglaterra, Irlanda do Norte, França, Suíça e Holanda), Asiático (China) e Oceania (Austrália) no que tange a publicação sobre a temática estudada.

Com efeito, observou nas produções publicadas a importância da conscientização de que os transtornos humor representam um sério problema de saúde pública, deve ser pesquisado a fundo as alterações neuropsicológicas como parte fundamental para auxiliar na promoção da saúde mental, provendo o bem-estar geral, a fim de melhorar a vida de pessoas acometidas por eles. Os estudos encontrados trazem como aspecto metodológico, em sua maioria, a revisão sistemática, seguido de estudos com metanálise, transversais e longitudinais e de intervenção, que contribuíram para levantar informações gerais sobre os aspectos dos transtornos de humor e das alterações neuropsicológicas, incluindo pesquisas recentes, testes utilizados em diagnósticos e possibilidades de tratamento.

Quanto aos estudos por grupos de patologias, houve mais estudos relacionados aos transtornos de humor $(57,1 \%)$, do que aos aspectos relacionados às alterações neuropsicológicas (42,9\%). Os transtornos bipolares foram os mais abordados na categoria transtornos de humor, seguido de tentativa de suicídio, transtorno depressivo, impulsividade, anedonia, transtorno de ansiedade, insegurança, desesperança, afetividade, transtorno de ansiedade e depressão e transtorno depressivo maior. Cada transtorno de humor possui características específicas que os tornam únicos e demandam tratamento inerente, e o que os une nessa categoria são os sintomas típicos (alteração no humor ou no afeto, comportamento, jeito de sentir e pensar), nos quais comprometem a capacidade funcional física, social e a vida profissional. No que se refere às alterações neuropsicológicas, a esclerose múltipla foi a mais estudada, seguida de demência, doença de Parkinson, doença de Alzheimer, esquizofrenia, doença vascular e cardiovascular. As alterações mais apontadas nessas patologias estão relacionadas aos déficits na memória, atenção, 
concentração, flexibilidade cognitiva e abstração, porém, ainda há controvérsias a respeito da gravidade ou magnitude desses déficits.

Cabe destacar algumas limitações do presente estudo, como o fato de que os descritores utilizados na busca por artigos podem não ter captado, de forma precisa, todos os estudos sobre a temática investigada. Isso explica o número elevado de artigos encontrados fora da temática, em si, e o número reduzido considerado na análise final. Para tanto, ressalta-se a importância de aprofundar as investigações na área aqui estudada, uma vez que os impactos dos transtornos de humor e as alterações neuropsicológicas influenciam negativamente na vida do indivíduo, provocando agravos ao desenvolvimento biopsicossocial, com destaque para a esfera cognitiva e das funções executivas.

\section{Referências}

Alzheimer's disease: Which tools for the differential diagnosis? L'encephale, 44(1), 52-58. https://doi.org/10.1016/j.encep.2017.03.002

American Psychiatric Association [APA]. (2014). Manual diagnóstico e estatístico de transtornos mentais: DSM-5. (5a ed.), Artmed.

Arent, M. K., de Pereira, A. P. A., Sato, H. K., \& Gomes Jr, C. (2019). Avaliação neuropsicológica em adultos com Esclerose Múltipla: Revisão sistemática. Psicologia Argumento, 37(95), 125-142. http://dx.doi.org/10.7213/psicolargum.37.95.AO07

Baune, B. T., \& Malhi, G. S. (2015). A review on the impact of cognitive dysfunction on social, occupational, and general functional outcomes in bipolar disorder. Bipolar disorders, 17, 41-55. https://doi.org/10.1111/bdi.12341

Belleville, S., Fouquet, C., Hudon, C., Zomahoun, H. T. V., \& Croteau, J. (2017). Neuropsychological measures that predict progression from mild cognitive impairment to Alzheimer's type dementia in older adults: a systematic review and meta-analysis. Neuropsychology review, 27(4), 328-353. Retrieved from https://link.springer.com/article/10.1007/s11065-017-9361-5

Bortolini, S. M. (2016). Fatores associados ao suicídio como violência autoinfligida entre idosos: revisão sistemática. https://repositorio.ufsc.br/handle/123456789/168214.

Bosaipo, N. B., Borges, V. F., \& Juruena, M. F. (2017). Transtorno bipolar: uma revisão dos aspectos conceituais e clínicos. Medicina (Ribeirão Preto), 50(Supl 1), 72-84. http://dx.doi.org/10.11606/issn.2176-7262.v50isupl1.p72-84

Bresin, K. (2019). Impulsivity and aggression: A meta-analysis using the UPPS model of impulsivity. Aggression and violent behavior, 48, 124-140. https://doi.org/10.1016/j.avb.2019.08.00

Brunt, A., Albines, D., \& Hopkins-Rosseel, D. (2019). The effectiveness of exercise on cognitive performance in individuals with known vascular disease: a systematic review. Journal of clinical medicine, 8(3), 294. https://doi.org/10.3390/jcm8030294

Cambridge, O. R., Knight, M. J., Mills, N., \& Baune, B. T. (2018). The clinical relationship between cognitive impairment and psychosocial functioning in major depressive disorder: A systematic review. Psychiatry research, 269, 157-171. https://doi.org/10.1016/j.psychres.2018.08.033

Cao, B., Zhu, J., Zuckerman, H., Rosenblat, J. D., Brietzke, E., Pan, Z., ... \& McIntyre, R. S. (2019). Pharmacological interventions targeting anhedonia in patients with major depressive disorder: A systematic review. Progress in Neuro-Psychopharmacology and Biological Psychiatry, 92, 109-117. https://doi.org/10.1016/j.pnpbp.2019.01.002

Cardoso, T., Bauer, I. E., Meyer, T. D., Kapczinski, F., \& Soares, J. C. (2015). Neuroprogression and cognitive functioning in bipolar disorder: a systematic review. Current psychiatry reports, 17(9), 75. https://doi.org/10.1007/s11920-015-0605-X.

Combs, H. L., Folley, B. S., Berry, D. T., Segerstrom, S. C., Han, D. Y., Anderson- Mooney, A. J., ... \& van Horne, C. (2015). Cognition and depression following deep brain stimulation of the subthalamic nucleus and globus pallidus pars internus in Parkinson's disease: a meta-analysis. Neuropsychology review, 25(4), 439-454. https://doi.org/10.1007/s11065-015-9302-0

Cromarty, R. A., Elder, G. J., Graziadio, S., Baker, M., Bonanni, L., Onofrj, M., ... \& Taylor, J. P. (2016). Neurophysiological biomarkers for Lewy body dementias. Clinical Neurophysiology, 127(1), 349-359. https://doi.org/10.1016/j.clinph.2015.06.020

de Lima Argimon, I. I., Paloski, L. H., Farina, M., \& Irigaray, T. Q. (2016). Aplicabilidade do Inventário de Depressão de Beck-II em idosos: Uma revisão sistemática. Avaliação Psicológica, 15, 11-17. Retrieved from https://www.redalyc.org/articulo.oa?id=335049854003

de Oliveira Miranda, I. M., Zeuri, E., Tank, K., Barbosa, J. G., Antônio Filho, N., \& de Rezende, L. F. (2018). Caracterização da ideação suicida em estudantes universitários. Revista da Universidade Vale do Rio Verde, 16(1). http://dx.doi.org/10.5892/ruvrd.v16i1.3731

Dickinson, T., Becerra, R., \& Coombes, J. (2017). Executive functioning deficits among adults with Bipolar Disorder (types I and II): A systematic review and meta-analysis. Journal of affective disorders, 218, 407-427. https://doi.org/10.1016/j.jad.2017.04.010

Edwards, C. J., Cella, M., Tarrier, N., \& Wykes, T. (2015). Investigating the empirical support for therapeutic targets proposed by the temporal experience of pleasure model in schizophrenia: A systematic review. Schizophrenia Research, 168(1-2), 120-144. https://doi.org/10.1016/j.schres.2015.08.013.

Fernandes, C., Esper, C. D. A., \& Faiman, C. J. S. (2017). Esquizofrenia e direção veicular: uma revisão sistemática da literatura. Saúde, Ética \& Justiça, 22(2), 72-80. https://doi.org/10.11606/issn.2317-2770.v22i2p72-80 
Fields, J. A. (2017). Cognitive and neuropsychiatric features in Parkinson's and Lewy body dementias. Archives of Clinical Neuropsychology, 32(7), 786-801. https://doi.org/10.1093/arclin/acx085

Gibson, J. A., Ackling, E., Bisson, J. I., Dobbs, T. D., \& Whitaker, I. S. (2018). The association of affective disorders and facial scarring: Systematic review and meta-analysis. Journal of affective disorders, 239, 1-10. https://doi.org/10.1016/j.jad.2018.06.013

Gomes, I. S., \& Caminha, I. (2014). Guia para estudos de revisão sistemática: uma opção metodológica para as Ciências do Movimento Humano. Movimento (ESEFID/UFRGS), 20(1), 395-411. https://doi.org/10.22456/1982-8918.41542

Gomes, T. E. B., \& Ivo, O. P. (2017). Sistematização da assistência de Enfermagem em mulheres com sintomatologia depressiva: uma revisão sistemática. ID on line REVISTA DE PSICOLOGIA, 11(38), 835-848. https://doi.org/10.14295/idonline.v11i38.957

Harrison, J. K., Noel-Storr, A. H., Demeyere, N., Reynish, E. L., \& Quinn, T. J. (2016). Outcomes measures in a decade of dementia and mild cognitive impairment trials. Alzheimer's research \& therapy, 8(1), 1-10. https://doi.org/10.1186/s13195-016-0216-8

Johnen, A., Landmeyer, N. C., Bürkner, P. C., Wiendl, H., Meuth, S. G., \& Holling, H. (2017). Distinct cognitive impairments in different disease courses of multiple sclerosis-a systematic review and meta-analysis. Neuroscience \& Biobehavioral Reviews, 83, 568-578. https://doi.org/10.1016/j.neubiorev.2017.09.005

Júnior, J. A. S. H., Fernandes, A. L. A. F., Medeiros, A. G. A. P., Vasconcelos, C. A. C., Amorim, L. L. L., Queiroga, M. F. S., \& Araújo, R. C. T. (2018). Hopelessness in the elderly: A systematic review. MOJ Gerontology and Geriatrics, 3, 273-278. Retrieved from https://www.researchgate.net/profile/CarlosVasconcelos-7/publication/326901864_Hopelessness_in_the_elderly_a_systematic_review/links/5b7809924585151fd11d7c1a/Hopelessness-in-the-elderly-asystematic-review.pdf

Karantzas, G. C., Romano, D., \& Lee, J. (2019). Attachment and aged care: a systematic review of current research. Current opinion in psychology, 25, 37-46. https://doi.org/10.1016/j.copsyc.2018.02.016

Kliemann, A., Böing, E., \& Crepaldi, M. A. (2017). Fatores de risco para ansiedade e depressão na gestação: Revisão sistemática de artigos empíricos. Mudanças-Psicologia da Saúde, 25(2), 69-76. Retrieved from https://www.psicologiadasaude2021.com.br/arquivos/5e78bb5252440.pdf

McHugh, C. M., Lee, R. S. C., Hermens, D. F., Corderoy, A., Large, M., \& Hickie, I. B. (2019). Impulsivity in the self-harm and suicidal behavior of young people: a systematic review and meta-analysis. Journal of psychiatric research, 116, 51-60. https://doi.org/10.1016/j.jpsychires.2019.05.012

Medrano-Martinez, P., Ramos-Platon, M. J., \& Peraita-Adrados, R. (2018). Neuropsychological alterations in narcolepsy with cataplexy: a review. Revista de neurologia, 66(3), 89. Retrieved from https://europepmc.org/article/med/29368327

Mitolo, M., Venneri, A., Wilkinson, I. D., \& Sharrack, B. (2015). Cognitive rehabilitation in multiple sclerosis: a systematic review. Journal of the Neurological Sciences, 354(1-2), 1-9. https://doi.org/10.1016/j.jns.2015.05.004

Moher, D., Liberati, A., Tetzlaff, J., Altman, D. G., \& Prisma Group. (2009). Preferred reporting items for systematic reviews and meta-analyses: the PRISMA statement. PLoS med, 6(7), e 1000097. https://doi.org/10.1371/journal.pmed.1000097

Mondragón, J. D., Maurits, N. M., \& De Deyn, P. P. (2019). Functional neural correlates of anosognosia in mild cognitive impairment and alzheimer's disease: a systematic review. Neuropsychology review, 29(2), 139-165. https://doi.org/10.1007/s11065-019-09410-x

Nair, R., Martin, K. J., \& Lincoln, N. B. (2016). Memory rehabilitation for people with multiple sclerosis. Cochrane Database of Systematic Reviews, (3). https://doi.org/10.1002/14651858.CD008754.pub3.

Newton, D. F., Naiberg, M. R., \& Goldstein, B. I. (2015). Oxidative stress and cognition amongst adults without dementia or stroke: Implications for mechanistic and therapeutic research in psychiatric disorders. Psychiatry research, 227(2-3), 127-134. https://doi.org/10.1016/j.psychres.2015.03.038

Passos, I. C., Mwangi, B., Vieta, E., Berk, M., \& Kapczinski, F. (2016). Areas of controversy in neuroprogression in bipolar disorder. Acta Psychiatrica Scandinavica, 134(2), 91-103. https://doi.org/10.1111/acps.12581

Samamé, C., Martino, D. J., \& Strejilevich, S. A. (2015). An individual task meta-analysis of social cognition in euthymic bipolar disorders. Journal of Affective Disorders, 173, 146-153. https://doi.org/10.1016/j.jad.2014.10.055

Santa, N. D., \& Cantilino, A. (2016). A Review of Literature on Suicide among Doctors and Medical Students. Revista Brasileira de Educação Médica, 40(4), 772-780. https://doi.org/10.1590/1981-52712015v40n4e00262015

Stratford, H. J., Cooper, M. J., Di Simplicio, M., Blackwell, S. E., \& Holmes, E. A. (2015). Psychological therapy for anxiety in bipolar spectrum disorders: a systematic review. Clinical psychology review, 35, 19-34. https://doi.org/10.1016/j.cpr.2014.11.002

Szmulewicz, A. G., Valerio, M. P., Smith, J. M., Samamé, C., Martino, D. J., \& Strejilevich, S. A. (2017). Neuropsychological profiles of major depressive disorder and bipolar disorder during euthymia. A systematic literature review of comparative studies. Psychiatry research, 248, 127-133. https://doi.org/10.1016/j.psychres.2016.12.031

Tucker, J. D., \& Bertke, A. S. (2019). Assessment of cognitive impairment in HSV-1 positive schizophrenia and bipolar patients: systematic review and metaanalysis. Schizophrenia research, 209, 40-47. https://doi.org/10.1016/j.schres.2019.01.001

Wojcik, C. M., Beier, M., Costello, K., DeLuca, J., Feinstein, A., Goverover, Y., \& National MS Society Cognition Work Team. (2019). Computerized neuropsychological assessment devices in multiple sclerosis: A systematic review. Multiple Sclerosis Journal, 25(14), 1848-1869. https://journals.sagepub.com/doi/full/10.1177/1352458519879094 